\title{
CAMPESINATO, MOVIMENTOS SOCIAIS POPULARES E A CONSTRUÇÃO DA HEGEMONIA: CONTRIBUIÇÕES DO PENSAMENTO DE GRAMSCI
}

\author{
Guilherme Goretti Rodrigues iD1, Dileno Dustan Lucas de Souza iD2, Ramofly \\ Bicalho iD 3
}

Resumo: Este artigo tem por objetivo compreender o lugar do campesinato no processo revolucionário, tomando como reflexão o protagonismo dos movimentos sociais populares no contexto brasileiro. Para tanto, o pensamento filosófico, social, político-econômico e militante de Antônio Gramsci é essencial para refletirmos e analisarmos acerca das tarefas políticas e educativas da classe trabalhadora para a construção de outra hegemonia, de homens e mulheres de novo tipo, que configure na superação do capitalismo e consequente fim da exploração humana e de classe. Tais tarefas, como possibilidade histórica real, envolvem, no pensamento gramsciano, aspectos tais como a elevação da consciência crítica das massas populares, o papel dos intelectuais orgânicos e do partido. Apesar de considerar o protagonismo operário na condução do processo revolucionário, em condições historicamente situadas e determinadas (a Itália e a Europa no início do século XX), Gramsci não se abstém de analisar a condição do/da camponês/a no contexto italiano, deixando uma importante contribuição para o atual tempo histórico. Trata-se de um trabalho de cunho teórico e qualitativo, que busca traçar aspectos do pensamento de Gramsci e atualizá-los para a realidade brasileira, utilizando também de outros autores do campo marxista. Em um momento de emergência do discurso conservador e fascista, faz-se necessário recuperar os pressupostos revolucionários, a causalidade histórica, que culmine efetivamente na construção da hegemonia do conjunto da classe trabalhadora.

Palavras-chave: Hegemonia; Campesinato; Políticas Públicas.

\section{PEASANTRY, POPULAR SOCIAL MOVEMENTS AND THE CONSTRUCTION OF HEGEMONY: CONTRIBUTIONS OF GRAMSCI'S THOUGHT}

Abstract: Antonio Gramsci's philosophical, social, political-economic and militant thought is essential for us to reflect and analyze the political and educational tasks of the working class for the construction of another hegemony, of men and women of a new type, which configures the overcoming of capitalism and the consequent end of human and class

\footnotetext{
${ }^{1}$ Mestre em Educação Universidade Federal de Juiz de Fora (UFJF). Doutorando em Educação pelo PPGEDUC da Universidade Federal Rural do Rio de Janeiro. E-mail: guilhermegoretti.geografia@gmail.com.

${ }^{2}$ Doutor em educação pela Universidade Federal do Rio Grande do Sul (UFRGS). Professor na Universidade Federal de Juiz de Fora (UFJF). E-mail: dilenodustand@gmail.com.

${ }^{3}$ Doutor em Educação pela Universidade Estadual de Campinas (UNICAMP). Professor Associado III na Universidade Federal Rural do Rio de Janeiro (UFRRJ). E-mail: ramofly@gmail.com.
} 
exploitation. Such tasks, as a real historical possibility, involve, in Gramscian thought, aspects such as the elevation of the critical consciousness of the popular masses, the role of organic intellectuals and the party. Despite considering the protagonism of the workers in conducting the revolutionary process, in historically situated and determined conditions (Italy and Europe at the beginning of the 20th century), Gramsci does not refrain from analyzing the condition of the peasant in the Italian context, leaving an important contribution to the current historical time. In this sense, this article aims to understand the place of the peasantry in the revolutionary process, taking as a reflection the protagonism of popular social movements in the Brazilian context. It is a work of a theoretical and qualitative nature, which seeks to trace aspects of Gramsci's thought and update them to the Brazilian reality, also using other authors from the Marxist field. In a moment of emergence of the conservative and fascist discourse, it is necessary to recover the revolutionary assumptions, the historical causality, which effectively culminates in the construction of the hegemony of the working class as a whole.

Keywords: Hegemony; Peasantry; Public policy.

\section{Introdução}

[...] é preciso reorganizar as grandes massas e se tornar um grande partido, o único partido no qual a população trabalhadora veja a expressão de sua vontade política, o local de manifestação de seus interesses imediatos e permanentes na história (GRAMSCI, 1987, p. 108).

O trecho acima mencionado está inserido no artigo sobre a "crise italiana", publicado no periódico L'ordine Nuovo. No contexto em que foi escrito, em 1924, o fascismo já havia penetrado no Estado italiano4, tendo a figura de Mussolini no poder, cujo resultado foi a corrosão e pauperização das condições sociais e político-econômica da classe trabalhadora e a perseguição de suas formas de organização política. Naquele tempo histórico, os princípios fascistas ganharam fôlego e penetraram no conjunto da sociedade, cujo resultado histórico se desdobrou com a segunda guerra mundial, com custos inestimáveis para a humanidade. Como afirma Gramsci (1977, p.123-124) o fascismo chegou ao poder por meio da organização da pequena burguesia, "ébria de ódio contra a classe operária, que conseguia, graças à força de sua organização, atenuar os contragolpes da crise capitalista em sua direção".

Quase cem anos após a publicação deste artigo, as condições para o conjunto da classe trabalhadora no Brasil não parecem estar melhores, cuja crise do capitalismo, que teve início no final da década passada, levou a reorganização da classe hegemônica e a reestruturação produtiva do capital por meio das contrarreformas que, de imediato, já aumentam o pauperismo, a precarização e o desemprego dos trabalhadores/as. No campo, verifica-se o

4 Do ponto de vista histórico, o fascismo italiano se consolida em outubro de 1922, na chamada "Marcha sobre Roma", que preparou o golpe de Estado e a chegada de Mussolini ao poder. 
aumento da violência e o discurso de ódio contra os/as camponeses/as, a partir do avanço desenfreado do latifúndio, do agronegócio e da mineração, colocando em risco povos e comunidades tradicionais e a biodiversidade em geral. Com a ruptura em 2015, com o Partido dos Trabalhadores (PT) - por meio do golpe parlamentar contra a ex-presidente Dilma Rousseff -, a burguesia inicia a fase mais ortodoxa do neoliberalismo, por meio das reformas trabalhistas e da previdência, o teto de gastos com saúde e educação, a privatização e desmonte de setores públicos, aliada ao discurso ultraconservador. Ou seja, tal como no tempo histórico vivido por Gramsci, presencia-se o caráter destrutivo do capital e a violência da burguesia contra a classe trabalhadora.

De acordo com Simionatto (2011, p. 35) o pensamento de Gramsci gira em torno da "sensibilidade para a luta, para a construção de uma nova ordem social, de uma nova cultura, de um novo projeto político". Vivendo em uma realidade de profundas transformações e desigualdades provocadas pelo desenvolvimento capitalista, Gramsci vê na classe operária a vanguarda da revolução, sobretudo, nas experiências da Revolução Russa de 1917 e nas ocupações de fábrica de Turim, formando o conselho dos operários, entre 1919-1920 (conhecido como biênio vermelho). Contudo, são nas notas e escritos sobre a questão meridional que se tem uma importante contribuição de Gramsci (1987) para o entendimento do papel do campesinato no processo revolucionário e, especialmente, nas possíveis atualizações que podemos fazer para a realidade brasileira. Assim, este artigo tem por objetivo compreender o lugar do campesinato no processo histórico, tomando como reflexão o protagonismo que os movimentos sociais populares, que se organizam no campo, exercem no contexto brasileiro.

O atual bloco no poder ${ }^{5}$, que se compõe desde 2015, é a expressão do ódio da burguesia contra a classe trabalhadora, que se valeu da adesão da classe média e de parte dos/das trabalhadores/as, sob o discurso de crise social, política e econômica, o que levou a constante desestabilização do governo PT, sobretudo, após as eleições de 2014. Entretanto, não podemos nos abster de analisar a realidade da própria ação dos movimentos sociais populares e sindicatos organizados pela classe trabalhadora. Isso porque as conquistas e avanços nos direitos dos/das trabalhadores/as verificados nos governos Lula-Dilma (2003-2015) se contrastaram com as contradições, tais como a coalização do PT com partidos burocráticos e de tendências conservadoras, da aliança com a burguesia nacional e o aumento do lucro dos bancos (BOITO JUNIOR, 2005), além do próprio aparelhamento dos movimentos sociais no Estado, o que levou a estes próprios movimentos a apostarem nas reformas e nas concessões das políticas públicas (SOUZA, 2007) ou compensatórias como a causa última.

\footnotetext{
${ }^{5}$ Tal conceito, como nos lembra Boito Junior (2005, p.54), designa a "unidade contraditória da burguesia organizada como classe dominante", ou seja, a classe burguesa não é um bloco monolítico, mas possui diversas frações que correspondem a um determinado setor produtivo, e que também estão em disputa para a exercer sua dominação e hegemonia em determinada conjuntura ou tempo histórico.
} 
A falta de uma avaliação interna dessas contradições levou a um arrefecimento de muitas lutas populares, no que tange a formação de uma consciência crítica e da construção de um bloco popular que apontasse efetivamente para a condução do processo revolucionário. Não que as ocupações, manifestações e lutas na cidade e no campo não continuem acontecendo, mas não é possível defender pautas - sem ampla reflexão - que da mesma forma em que concedia direitos aos trabalhadores/as, abria condições para o aumento do lucro da classe burguesa, ou da expansão do agronegócio, do latifúndio etc.

Em uma sociedade de classes, as lutas entre antagonistas não só são inerentes ao capitalismo, como é impossível apostar na acomodação ou consenso entre trabalhadores/as e a burguesia. E a história nos ensina que o reformismo ou a revolução passiva, na acepção gramsciana, só tende a levar a novas derrotas para a classe trabalhadora. Portanto, precisamos encarar e recuperar a causalidade histórica, isto é, como se estrutura o modo de produção capitalista, seus efeitos nocivos ao longo do processo histórico, recuperando os pressupostos revolucionários que caminhem para a construção de outra sociedade, de outra hegemonia. Para Gramsci (2007) a hegemonia trata-se tanto do poder e dominação ético-política, quanto econômica, ou seja, relação entre estrutura e superestrutura. A questão é: como criar condições objetivas e subjetivas para a superação do capitalismo, como possibilidade histórico-concreta? Enquanto não criarmos tais estratégias e constantes avaliações da atual conjuntura, renovando as alianças, a direção e o projeto popular, continuaremos a ver reproduzindo os horrores e as mortes no campo e na cidade e, mais, a estar passíveis diante da ameaça do ultraconservadorismo e fascismo.

Neste sentido, a formulação de Gramsci (1987) de que é preciso reorganizar as massas para que elas vejam a expressão concreta de sua vontade política é fundamental, na medida em que somente um programa e projeto efetivamente construído no terreno popular é que tem condições históricas de derrotar o capitalismo e promover a emancipação humana. Reorganização que requer educar as massas, gerar o consenso e a vontade coletiva para a luta político-econômica.

Para tanto, dividiremos este artigo em três momentos. Além da introdução, que buscou trazer um breve balanço do atual tempo histórico e a necessidade de reorganização da classe trabalhadora, o segundo subtópico apresenta as principais contribuições de Gramsci no estudo sobre a questão meridional, em que analisa a situação do camponês/a na Itália, fortalecendo a ideia da auto-organização e autoatividade dos camponeses e sua aliança com o operário. Contrário às teses que apontam o fim do campesinato, este se apresenta cada vez mais vivaz e indispensável para a revolução. O terceiro subtópico trata de caracterizar historicamente o campesinato, trazendo as experiências políticas e educativas e as tarefas dos movimentos sociais populares para a construção de outro projeto de sociedade e da formação de homens e mulheres de novo tipo (na concepção gramsciana). Por fim, concluímos com algumas considerações e reflexões acerca da importância da análise do campesinato, a valorização das experiências construídas pelos 
sujeitos individuais e coletivos, assim como dos desafios frente ao atual contexto social, político e econômico.

\section{A Questão Meridional e a aliança operário-camponesa}

No ano de 1926, Gramsci escreve "alguns temas da questão meridional" (1987) para situar o camponês/a no contexto italiano. Naquele momento, no início do século $\mathrm{XX}$, o capitalismo na Itália produziu um desenvolvimento contraditório e desigual: a região norte como aquela concentradora de indústrias, das cidades e do operariado; e a região sul (meridional) composta basicamente por camponeses e a margem deste processo de desenvolvimento. De acordo com Gramsci (1987, p. 154), o bloco agrário do sul era composto pela "grande massa camponesa, amorfa e desagregada; os intelectuais da pequena e média burguesia rural e, por fim, os grandes proprietários de terra e os grandes intelectuais". Ou seja, para Gramsci, o/a camponês/a estava ligado às ações da burguesia e dos grandes proprietários de terra, assim como da igreja católica e dos clérigos (sob influência do Vaticano), fato que impedia o desenvolvimento de uma consciência coletiva que imputasse em uma autoatividade e auto-organização dos camponeses.

Portanto, como superar essa condição do campesinato no sul? Gramsci, na sua atividade política e intelectual, rejeitava as teses reformistas - fato que levou a muitas derrotas da classe trabalhadora e o seu próprio afastamento do Partido Socialista Italiano (PSI), o que o levou a fundar o Partido Comunista Italiano (PCI). Em "alguns temas da questão meridional" (1987), salienta que não era a favor da fórmula de dar terra aos camponeses, mas via a necessidade de que este ato estivesse vinculado "numa ação revolucionária geral das duas classes aliadas, sob a direção do proletariado industrial" (GRAMSCI, 1987, p. 138), ou seja, é na derrota da classe burguesa e dos grandes proprietários de terra que se superaria 0 estágio em que se encontrava o campesinato no sul e, concomitante, toda estrutura agrária. A ação revolucionária das duas classes (operário e camponês/a) deveria caminhar para a formação de um bloco e frente única, despojada dos corporativismos e burocratismos, criando uma vontade coletiva em torno de uma direção e projeto de sociedade, controlado pelos trabalhadores/as.

Durante o período de cárcere ${ }^{6}$, em que produziu um grande volume de textos e reflexões de natureza político-econômica, histórico-social, filosófica etc. - que reunidos deram origem aos "cadernos do cárcere" -, Gramsci retoma e complexifica a análise da questão meridional e a situação dos camponeses. De acordo com ROIO (2007, p. 67) "havia diferenças culturais valorativas que distinguiam as diversas regiões de origem dos segregados, 0 que seria um impeditivo para se colocar a Itália meridional dentro de um mesmo enquadramento", o que faz com que Gramsci trabalhe com a expressão de "grupos subalternos", para buscar analisar tais diferenças e diversidades no contexto italiano.

6 Gramsci é preso em novembro de 1926 pelo governo fascista, onde permanece até seu falecimento em 1937. 
No caderno 25, dedicado a história dos grupos sociais subalternos, há uma importante formulação que reforça a posição dos camponeses perante as classes dominantes e a necessidade de superação dessa dominação:

A história dos grupos sociais subalternos é necessariamente desagregada e episódica. É indubitável que, na atividade histórica destes grupos, existe tendência à unificação, ainda que em termos provisórios, mas esta tendência é continuamente rompida pela iniciativa dos grupos dominantes e, portanto, só pode ser demonstrada com o ciclo histórico encerrado, se este se encerra com sucesso. Os grupos subalternos sofrem sempre a iniciativa dos grupos dominantes, mesmo quando se rebelam e insurgem: só a vitória "permanente" rompe, e não imediatamente, a subordinação (GRAMSCI, 2002, p. 135).

Apesar da condição de subalternos, existia uma tendência à unificação, ou seja, o camponês/a não era visto como sujeito passivo ou que não tinha história, mas extremamente estratégico para romper com a subordinação imposta pela classe dominante. O que Gramsci reivindica é a necessidade das próprias massas camponesas em serem dirigentes, formando a aliança operário-camponesa, com força histórica para construir outra hegemonia.

Contudo, ressalta-se que Gramsci não escrevia de forma panfletária, isto é, não adianta apenas a agitação das massas populares se não dão a elas uma direção e um projeto claro. Como afirma, "nenhuma ação de massa é possível se a massa mesma não está convencida dos fins que deseja atingir e dos métodos a aplicar" (GRAMSCI, 1987, p. 146). Por isso, dentre os diversos temas abordados por Gramsci, chama atenção, para os objetivos deste trabalho, suas contribuições acerca da função do partido, dos intelectuais orgânicos e da elevação do nível de consciência crítica das massas populares.

De acordo com Gramsci (2014, p. 257) "numa determinada sociedade, ninguém é desorganizado e sem partido, desde que se entendam organização e partido num sentido amplo, e não formal". O partido em seu sentido ampliado seria uma instância coletiva que atua para elaborar e difundir determinada ideologia (concepção de mundo), que organiza uma vontade coletiva, atuando tanto para a conservação, quanto para a transformação das relações sociais. Assim, por exemplo, a Igreja atuaria como um partido, pois ela difunde uma determinada ideologia, educa o modo de agir, pensar e sentir das massas populares. Do mesmo modo é a classe dominante (burguesa), que educa as massas a partir de sua concepção de mundo.

É neste sentido de partido ampliado que também aparece a função dos intelectuais orgânicos, ou seja, cada classe cria "uma ou mais camadas de intelectuais que Ihe dão homogeneidade e consciência da própria função, não apenas no campo econômico, mas também no social e político" (GRAMSCI, 2001 , p. 15). Por isso, os intelectuais devem ser aqueles capazes de realizar a soldura com as massas populares, dando-lhe direção em torno de um projeto e concepção de mundo - e não aqueles que se distanciam ou se afirmam como uma casta intelectual apartada da classe a que pertencem.

Assim, construir o bloco operário-camponês/a é entender o seu papel e sua tarefa política e educativa para com o conjunto das camadas populares, no sentido de elaborar e difundir uma ideologia que seja expressão da vontade da 
classe trabalhadora, criando condições para que ela dispute e conquiste a hegemonia. Tal aspecto político e educativo, como condição para sair da subalternidade, requer a elevação do nível de consciência crítica das massas, isto é, a passagem do senso comum para o bom senso, dando consciência e criticidade histórica para homens e mulheres, para que compreendam a realidade em que vivem, seu lugar na produção material da vida, sua condição de expropriado e explorado pelo modo de produção capitalista, para que possam construir o edifício da liberdade e a emancipação humana.

Por isso, Gramsci chama atenção para a formação de homens e mulheres de novo tipo, isto é, que não sejam de única atividade, mas sim completos (sem dissociação entre o trabalho manual e intelectual), e que isso só seria possível por meio da reforma intelectual e moral da sociedade, por meio da revolução da classe trabalhadora e superação do capitalismo.

Embora em condições historicamente determinadas e situadas na Itália, a questão meridional abre advertências e possibilidades para as análises da nossa atual conjuntura. Isso não significa transferir de forma automática e mecânica as considerações de Gramsci sobre o campesinato para a nossa realidade, afinal, como o próprio ressalta, a questão camponesa na Itália "não é a questão camponesa e agrária em geral" (GRAMSCI, 1987, p. 139). Em cada país o campesinato se desenvolveu de uma forma, cabendo a nós compreender e refazer este processo histórico. Contudo, ao reforçar a aliança operário-camponês/a, como visceral no processo revolucionário, Gramsci não exclui a iniciativa política e organizativa dos camponeses, tampouco aposta nas correntes ortodoxas que afirmam que o campesinato está em via de extinção pelo capitalismo7.

Portanto, na realidade brasileira, quem são os subalternos e oprimidos pelo capitalismo e pela estrutura agrária que reproduz a desigualdade e violência? Quais são os movimentos sociais populares e sujeitos, individuais e coletivos, que se organizam e lutam para sair da subalternidade? Evidente que no Brasil, ao contrário do que Gramsci observou em seu tempo histórico, o campesinato não é 'desagregado' ou 'amorfo', pois se afirma com uma identidade política que é diversa para os grupos que o compõe - povos do campo, da floresta, das águas, quilombolas, indígenas etc. Trata-se de grupos que possuem experiências históricas de luta contra a classe ruralista, o latifúndio, o agronegócio, a mineração, defendendo pautas relativas à reforma agrária, trabalho, educação, cultura, agroecologia etc.

Assim, buscaremos a seguir caracterizar e refletir sobre o campesinato e os movimentos sociais populares, suas experiências políticas e educativas, fazendo as correlações com as duas questões centrais até aqui abordadas: 0 seu lugar no processo revolucionário e a necessidade de preparação das massas populares para a construção de uma nova hegemonia.

\section{O campesinato brasileiro: caracterização histórica e as experiências dos movimentos sociais populares}

\footnotetext{
7 Algumas correntes do marxismo chegam a concordar que o socialismo só será possível quando houver a proletarização do campesinato. Para essa importante discussão, ver o trabalho de Guzmán e Molina (2013).
} 
Ao nos referirmos ao campesinato ou ao camponês/a, buscamos a diversidade na totalidade, ou seja, dar aquilo que Martins (1990, p.22) chama de "unidade das respectivas situações de classe", ressaltando, entretanto, que tais situações de classe ou da condição do campesinato se constituí no Brasil diferentemente daquele observado por Gramsci na Itália, ou de Marx na Inglaterra ou de Lênin na Rússia.

Pelo processo de formação social, política e econômica do Brasil, este campesinato é composto por uma diversidade de grupos com distintas características sócio-históricas e étnico-culturais, com matrizes, traços e influências dos indígenas, quilombolas, camponeses e imigrantes. Para estes grupos, a terra e o território são essenciais para a produção e reprodução de suas existências sociais, físicas, materiais, simbólicas e culturais. Neste sentido, as formas de organização destes sujeitos revelam como constroem seus padrões de sociabilidade, seus valores éticos e morais que imputam em uma determinada visão de mundo: o trabalho coletivo e a solidariedade, o uso comum e a relação recíproca com a terra, a diversidade produtiva e as trocas, os laços familiares e de parentesco etc. Ou seja, esta totalidade do campesinato (que abarca uma diversidade de modos de vida) vem acumulando experiências que, embrionárias ou não, conscientes ou não, possuem o caráter revolucionário, estão encarnadas em homens e mulheres do campo a possibilidade concreta de transformação, justamente por subverterem as estruturas materiais e subjetivas do capitalismo.

Neste sentido, é importante caracterizar e entender como essa subversão e modo de vida se desenvolve e contrasta a partir da formação de um capitalismo dependente no Brasil, do latifúndio e da herança colonialescravocrata, que ainda hoje se faz presente pelas relações sociais e de poder que reitera o racismo e a violência contra a população negra. Tal como Gramsci (1987) identificara na Itália o bloco agrário em disputa, no Brasil temse a grande massa diversa dos subalternos em antagonismo com a classe dominante ruralista. Ou seja, uma luta de classes perpetradas no campo, fruto das contradições do capitalismo e de uma estrutura agrária extremamente desigual e excludente.

Para Oliveira (2005, p.468) a nossa estrutura agrária permitiu "aos proprietários de terras e aos capitalistas/proprietários de terra a possibilidade histórica da apropriação da renda da terra", fato que levou a concentração fundiária, a expulsão e expropriação do/da camponês/a (por processos de violência física, material ou simbólica), cacifadas pelos direitos fundiários construídos historicamente, tais como a política de Sesmarias, da Lei de Terras de 1850 e do Estatuto da Terra de 1964, durante a ditadura civil-militar no Brasil| ${ }^{8}$.

8 Em síntese, as Sesmarias, como política estabelecida no século XVI, permitia que grandes extensões de terra ficassem sob o controle de um donatário. De acordo com Panini (1990), esse sistema foi a fonte da formação do latifúndio no Brasil. A Lei de Terras de 1850 estabelecia que o acesso a terra fosse feito por meio de contrato de compra e venda, além de regularizar as posses já existentes. Entretanto, os valores para sua aquisição e as relações de poder de um sistema escravocrata mantiveram grande parcela das massas camponesas à margem desta política. Por sua vez, o Estatuto da Terra de 1964 privilegiou e possibilitou a expansão da empresa agrícola e, dentro de um contexto de repressão militar, a violência 
Concomitante, as formas de exploração dos/das trabalhadores/as no campo também se alteraram, pois a chamada transição do trabalho escravo para o trabalho livre trouxe categorias, tais como: o meeiro, arrendatário, assalariado temporário ou permanente que, tendo ou não a terra, se vê submetidos por relações de exploração capitalistas e não-capitalistas - em alguns casos em situações análogas à escravidão. Ou seja, o capitalismo também cria e recria o trabalho camponês/a para garantir sua acumulação e reprodução de capital.

São a partir dessas contradições na estrutura agrária brasileira que emergem as lutas camponesas e as suas formas de organização. Canudos (1896), Cangaço (1870), Contestado (1912), são exemplos de organizações que, com distintos graus de reivindicação e objetivos em determinado período da história, expressaram as injustiças sociais, políticas e econômicas no campo, dado o privilégio histórico das classes dominantes. De acordo com Martins (1990), até a década de 1940 as organizações camponesas pautavamse em sua maioria pelo messianismo e banditismo. Entretanto, a partir dos anos de 1950, "a liga camponesa e o sindicato serão as formas mais importantes de organização e luta política dos camponeses" (MARTINS, 1990, p.67), recebendo a influência de partidos e suas linhas teóricas para com o campesinato - tal como o Partido Comunista Brasileiro (PCB).

Contudo, a ditadura militar no Brasil (1964-1985) significou na repressão aos camponeses e fechamento de partidos e sindicatos de esquerda. Somente com o esgotamento do seu modelo social e político-econômico que possibilitou novamente a efervescência de novos movimentos sociais populares, que nascem diretamente da organização dos camponeses ou que irão exercer influência sobre a população do campo. O Movimento dos Trabalhadores/as Rurais Sem Terra (MST), criado em 1984; o Partido dos Trabalhadores/as (PT) e a Central Única dos Trabalhadores/as (CUT), fundados em 1980 e 1983, respectivamente, são exemplos de movimentos, partidos e sindicatos que se constroem já no final da ditadura. A Igreja Católica, que em um primeiro momento apoiou o golpe de 1964 para conter a influência comunista, já na década de 1970 se reorientou frente à violência que a ditadura militar vinha causando. A Comissão Pastoral da Terra (CPT), fundada em 1975, e as Comunidades Eclesiais de Base (CEBs), que se espalharam entre as décadas de 1970 e 1980, buscaram organizar os camponeses, além de exercer e manter a influência da Igreja entre as populações do campo - se a entendemos também como um partido na acepção gramsciana.

$\mathrm{Na}$ longa marcha do campesinato brasileiro, podemos perceber como as organizações camponesas, do messianismo e banditismo até a influência dos partidos ou da igreja, também deram um salto qualitativo e quantitativo. Por exemplo, o MST tem se colocado na luta política e de classes de forma decisiva, denunciando o latifúndio e os ruralistas, ao passo que educando os trabalhadores/as e militantes. Em paralelo com as contribuições de Gramsci (1987), esse movimento é crucial, na medida em que camponeses/as

contra o camponês/a e suas formas de organização. Para uma discussão ampliada, ver Panini (1990) e Martins (1985). 
irrompem contra o senso comum, a opressão e influência da classe dominante, buscando estratégias e táticas para sair da condição de subalternidade.

Mesmo com a redemocratização em 1988 e as primeiras eleições diretas em 1989, a realidade da estrutura agrária brasileira e a condição dos camponeses continuaram dramáticas e reproduzindo as desigualdades. $O$ neoliberalismo empenhado na década de 1990, com todas as suas reformas e ajustes fiscais (privatizações; redução e desmonte dos serviços públicos; abertura do mercado para empresas estrangeiras; endividamento externo; etc.), ainda permanece como agenda política dos governos e do Estado. Ainda que com a eleição de Lula, do Partido dos Trabalhadores/as (PT), em 2003, e a continuidade do PT com Dilma (até 2015, em virtude do processo de impeachment), não modificou em termos estruturais a realidade agrária brasileira. Na mesma medida em que se avançavam as políticas públicas para o conjunto da classe trabalhadora - como medidas compensatórias, na tentativa conciliatória entre classe burguesa e classe trabalhadora -, via-se o compromisso do governo Lula-Dilma com a expansão das empresas ligadas ao agronegócio, aumento do latifúndio e o papel dos bancos privados, sobretudo, no que se refere aos financiamentos e concessão de crédito para o setor da agricultura patronal.

A aposta na política conciliatória levou ao aparelhamento de muitos movimentos e sindicatos, esquecendo-se da formação e balanço crítico, fato que contribuiu para que o bloco conservador e fascista conseguisse penetrar no conjunto da sociedade e se colocar no poder por meio de um governo (com a eleição de Jair Bolsonaro, em 2018) que ataca constante a classe trabalhadora e realiza uma política ainda mais ortodoxa do neoliberalismo, levando ao pauperismo social e o acirramento da violência e conflito no campo.

Portanto, o atual tempo histórico já nos coloca um primeiro desafio para os movimentos sociais populares que se organizam no campo: a reflexão crítica acerca se os sindicatos e partidos - e até mesmo a Igreja -, que se colocaram como aqueles que iriam organizar as lutas camponesas ainda têm como horizonte um projeto efetivamente popular, que altere a estrutura agrária, as injustiças e desigualdades no campo. Como afirma Gramsci (1987, p.146) "para ser capaz de governar como classe, o proletariado deve se despojar de todo resíduo corporativo, de todo preconceito ou incrustação sindicalista", ou seja, trazendo isso para nossa realidade, não é possível mais formar alianças com partidos (no sentido ampliado) que apostam nas reformas sem alterar a estrutura do capitalismo.

Como abordamos anteriormente, o campesinato no Brasil possui uma força histórica, vivendo em uma realidade de contradições e desigualdades. Essa posição que assume o/a camponês/a já lhe confere um lugar de protagonismo, de afirmação e resistência frente ao caráter destrutivo do capital. Quanto mais o capital se expande no campo, mais o/a camponês/a se afirma e luta contra as injustiças sociais, políticas, econômicas e ambientais. Neste sentido, quais as experiências que estes sujeitos individuais e coletivos vêm acumulando? Como se organizam em torno dos movimentos sociais populares e expressam suas demandas, pautas e lutas? 
Para além das iniciativas e influências dos sindicatos, partidos e da igreja, compreendemos que os movimentos sociais populares do campo carregam uma identidade política própria, possuem pautas e demandas a partir da realidade e das contradições em que vivenciam. Por isso, qualificamos os movimentos sociais populares como aqueles que são a expressão de sujeitos coletivos, homens e mulheres de carne e osso, que são oprimidos, explorados e expropriados pelo sistema capitalista. Mais do que um conceito, importa-nos aqui compreender como se dá a construção, afirmação e luta desses movimentos populares em uma realidade concreta.

Apesar de não darmos conta da diversidade das organizações populares no Brasil, podemos citar aquelas que se colocam de forma mais orgânica na realidade agrária, pela sua capacidade de adesão e mobilização dos sujeitos do campo.

Por exemplo, o Movimento dos Trabalhadores/as Rurais Sem Terra (MST) se constitui desde a década de 1980 como um movimento que possui um projeto e uma direção clara. A organização em torno da luta pela reforma agrária, ocupando as terras que não cumprem sua função social; a denúncia contra a violência e a violação com que se dá a expansão do agronegócio; a promoção da agroecologia em assentamentos, garantindo uma produção sustentável e sem uso de agrotóxicos, dentro dos marcos da autonomia e soberania alimentar; a defesa por uma Educação do Campo, definindo os princípios éticos, políticos e filosóficos do movimento social, possibilitando a formação de seu próprio quadro de intelectuais, são exemplos de ações que, na luta direta (manifestações, passeatas, ocupações, etc.) ou na formação política e educativa dos/das trabalhadores/as do campo, confrontam diretamente com a classe ruralista, com o latifúndio e com o capital.

Sobre o aspecto da ação do MST, ressalta-se como este movimento social pode ser entendido como um partido, pois elabora e difunde uma vontade coletiva. Como sinaliza Gramsci (2014), a construção da hegemonia se dá também pelo consenso, isto é, pela disputa no âmbito da sociedade civil de um projeto de sociedade. Ainda que não seja nosso objetivo nesse trabalho, a classe dominante (em que se inserem os ruralistas) também elabora e difunde sua ideologia por meio dos seus partidos (em sentido ampliado). A União Democrática Ruralista (UDR), a Sociedade Nacional de Agricultura (SNA), a Sociedade Rural Brasileira (SRB), a Associação Brasileira do Agronegócio (ABAG), o Instituto Brasileiro de Mineração (IBRAM) - e tantos outros que poderiam ser citados -, são exemplos de entidades que se constroem no âmbito da sociedade civil e representam determinada classe ou fração de classe ruralista. Por meio das mídias, tais como propagandas, jornais, revistas, ou até mesmo nas escolas, disputam e buscam o consenso das massas populares, especialmente, no caráter positivo do agronegócio ou da mineração - criminalizando, com isso, os movimentos sociais populares do campo, como o próprio MST. Além disso, tais entidades atuam no âmbito do Estado, criando blocos parlamentares que disputam e formulam políticas públicas em prol dos interesses da classe ruralista.

Por isso, a educação realizada pelos movimentos sociais populares do campo é fundamental, não só por elevar o nível de consciência crítica das 
massas populares, mas por gerar novas formas de agir, pensar e sentir, novos padrões de sociabilidade que não aqueles difundidos pela classe burguesa, portanto, novo tipo de homens e mulheres. É o que Gramsci (2001, p.82) atenta para o espírito de cisão, isto é, "a conquista progressiva da consciência da própria personalidade histórica", que deve ser construído pela classe subalterna em contraposição e ruptura com a ideologia da classe dominante.

Apesar, no caso do MST, das avaliações que precisam ser feitas especialmente na sua relação com o Partido dos Trabalhadores (PT) e o balanço dos governos Lula-Dilma entre 2003-2015 (BRANFORD, 2010), pelas ressalvas que fizemos anteriormente - , a sua atuação histórica e orgânica confere uma posição visceral no processo revolucionário, reafirmando o papel de protagonismo do campesinato brasileiro. Outros movimentos, tais como o das comunidades quilombolas (CONAQ) ou do conjunto de organizações indígenas, também são fundamentais e essenciais neste processo, sobretudo, nas denúncias de violação de direitos socioambientais, na luta antirracista e pela afirmação de seus modos de vida e demarcação de seus territórios. Tanto quilombolas, quanto indígenas, também acumulam experiências políticas e educativas que afirmam a organicidade de seus movimentos, assim como na construção de seus próprios intelectuais.

Em um período histórico de tantos retrocessos e da ameaça fascista, o papel do campesinato não só é importante e estratégico para a reversão desta realidade, mas precisa se rearticular em torno dos movimentos sociais populares para as novas lutas. Essas questões nos conduzem para a práxis, a ação concreta na realidade como possibilidade de superação e transformação das relações sociais e político-econômicas. Neste sentido se tem a importância, dentro do pensamento gramsciano, da filosofia da práxis, como aquela que centraliza o conjunto da classe trabalhadora, os subalternos, como sujeitos históricos, portadores do processo revolucionário:

A filosofia da práxis, ao contrário, não tende a resolver pacificamente as contradições existentes na história e na sociedade, ou melhor, ela é a própria teoria de tais contradições; não é instrumento de governo de grupos dominantes para obter o consentimento e exercer a hegemonia sobre as classes subalternas; é a expressão destas classes subalternas, que querem educar a si mesmas na arte de governo e que têm interesse em conhecer todas as verdades, inclusive as desagradáveis, e em evitar os enganos (impossíveis) da classe superior e, ainda mais, de si mesmas (GRAMSCI, 1999, p.388)

Portanto, estamos diante de um desafio e compromisso de recuperar a causalidade histórica e os pressupostos revolucionários, isto é, a luta de classes como característica fundante do modo de produção capitalista (que antagoniza burguesia e trabalhadores/as); assim como tomar a realidade como totalidade, para que seja efetivamente possível construir condições históricas para o processo revolucionário e a emancipação dos trabalhadores/as. Isso não se dará por meio do aparelhamento com o Estado e com a classe burguesa, ou por meio das reformas pontuais que, como nos mostra a história, só tem levado em novas derrotas e retrocessos para o conjunto da classe trabalhadora. Tampouco será possível se apostarmos na fragmentação e nas 
particularidades - como algumas linhas pós-modernas sugerem - para explicar o atual estágio de pauperismo e miséria humana.

Concomitante, como Gramsci (2014) salienta, é necessário que os próprios movimentos sociais superem a fase econômico-corporativista, que as reivindicações não sejam meramente voltadas para o próprio movimento, mas sim para todo o conjunto da classe trabalhadora. Diante da enorme riqueza e diversidade do campesinato brasileiro, tem-se o desafio de valorizar e elevar as experiências populares em curso, fazer a história junto com os subalternos, construindo estratégias que caminhem para a unidade de luta dos/das trabalhadores/as, soldando os movimentos sociais populares do campo e da cidade. Superar o senso comum, isto é, todas aquelas concepções impostas pela classe dominante de maneira passiva e opressora, é um árduo processo de "conhece-te a ti mesmo", a formulação da "própria concepção do mundo de maneira consciente e crítica", participando "ativamente na produção da história do mundo, ser o guia de si mesmo" (GRAMSCI, 1999, p. 94). É a passagem do senso comum para o bom senso, capaz de gerar a catarse, isto é, "a fase em que as ideologias geradas anteriormente se transformam em partido, entram em confrontação e lutam até que uma delas tenda a prevalecer" (GRAMSCI, 2014, p.41). Ou seja, que a classe trabalhadora possa formar uma frente única, um único partido que represente a unidade da classe trabalhadora, formado por operários e camponeses, para que seja efetivamente capaz de disputar, derrotar a burguesia e o capitalismo, e ser hegemonia. Daí a centralidade da filosofia da práxis, da ligação teoria-prática e da ação concreta na luta contra o capital.

Neste sentido, construir uma nova hegemonia é propor um novo projeto de sociedade, uma nova base ético-política e econômica, reconhecendo a insustentabilidade e o caráter destrutivo do capitalismo. Ressalta-se como o campesinato tem encaminhado, por meio das suas experiências individuais e coletivas, outras formas de produção e reprodução da vida material e subjetiva humana, recuperando a indissociável dimensão entre homem e natureza, o trabalho coletivo, a educação e a cultura como base para formação de homens e mulheres integrais ou de novo tipo (GRAMSCI, 2001). Novamente, o Movimento Sem Terra (MST) tem consolidado importantes atividades e ações políticas e educativas entorno da agroecologia, da Educação do Campo e da defesa das escolas do campo, da formação de lideranças, da luta pela Reforma Agrária, das manifestações e ocupações que assumem um caráter educativo e formativo para trabalhadores/as e militantes, contribuindo inestimavelmente na luta por outra hegemonia. Por sua vez, quilombolas e indígenas tem dado contribuições viscerais, tanto na luta pelos seus territórios e em defesa da biodiversidade, quanto na luta contra o racismo, que impera na sociedade brasileira de maneira estrutural e inerente a exploração capitalista.

Por outro lado, coloca-se como desafio a importância da formação dos intelectuais orgânicos da classe trabalhadora, como aqueles organizadores da cultura (GRAMSCI, 2001). Nascidos no terreno da própria classe ou por ela assimilada (caso dos intelectuais tradicionais, herdados de modos produção anteriores como, por exemplo, os clérigos), os intelectuais dão homogeneidade e direção entorno de uma determinada concepção de mundo, contribuindo 
para elevar o nível de consciência crítica das massas populares. Entretanto, não se trata de pensar os intelectuais como uma casta ou camada burocrática, mas na "dialética intelectuais-massa", desenvolvendo-se quantitativa e qualitativamente a "um movimento análogo da massa dos simples que se eleva a níveis superiores da cultura" (GRAMSCI, 1999, p. 104). Como ressalta Gramsci (1999, p.104), esse processo de formação dos intelectuais é "longo, difícil, cheio de contradições, de avanços e de recuos, de debandadas e reagrupamentos", de maneira que a sua ação é "submetida a duras provas".

Da mesma forma que a classe dominante possui seu quadro de intelectuais, difundindo uma concepção de mundo burguesa e capitalista, torna-se essencial que a classe trabalhadora forme seu próprio quadro de lideranças, sem qualquer tipo de hierarquização, isto é, que todos possam cumprir a função de dirigentes para com a classe. Atuação esta que não pode prescindir da construção do processo revolucionário, portanto ligado as experiências, vontades coletivas e lutas cotidianas dos subalternos. Como adverte Gramsci (2001, p. 53), em referência a Marx, o próprio educador precisa ser educado, para que não haja regressão, reacionarismo ou "motor exterior e momentâneo dos afetos e das paixões", mas a disciplina, a responsabilidade individual-coletiva, o método (filosofia da práxis), a ligação teoria-prática, enfim, processos que envolvem o diálogo permanente com os subalternos, a "inserção ativa na vida prática como construtor, organizador, persuasor permanente".

Construir e ser hegemonia requer a sensibilidade para a luta, a valorização das múltiplas experiências em curso, mesmo que com distintos graus de organicidade, mas fundamentais na luta contra o capital. Entende-se que a própria classe trabalhadora está sempre em processo de formação, em si e para si, de forma que esperar algo pronto e acabado (ou mesmo dentro de parâmetros idealizados) consiste em um erro, especialmente, por se furtar do processo de construção política e educativa da classe e dos sujeitos.

Em um tempo histórico de agudização da ofensiva do capital e do discurso ultraconservador, torna-se candente disputar as massas populares, apontando todas as contradições do capitalismo, seu caráter cada vez mais perverso e destrutivo, permitindo o espírito de cisão, a conquista gradativa da própria personalidade histórica, pois enquanto sujeitos concretos, homens e mulheres de carne e osso são capazes de mudar e fazer a história.

\section{Considerações Finais}

Este artigo pretendeu mostrar que o campesinato possui lugar e se constitui como elemento fundamental (junto ao operário) no processo revolucionário, especialmente quando abordamos brevemente sobre o MST, um dos principais movimentos sociais populares construídos pelos trabalhadores/as do campo. Entretanto, é preciso que analisemos tais movimentos, sobretudo, se defendemos e compreendemos a indispensável necessidade de preparação das massas populares para a construção de outra hegemonia, o que requer tarefas políticas e educativas no seio destes próprios movimentos populares - e essa também foi uma das nossas buscas ao trazer 
as contribuições da atividade intelectual, política e militante de Gramsci para a realidade brasileira.

Diz Gramsci (2002, p. 135) que "todo traço de iniciativa autônoma por parte dos grupos subalternos deve ser de valor inestimável para o historiador integral". O valor dessa formulação consiste na advertência de estarmos atentos para a história construída pelos subalternos, que é diversa dentro de uma totalidade social. Para o campesinato brasileiro, diríamos para a importância de valorizarmos as experiências em curso dos camponeses, dos quilombolas, dos indígenas, de homens e mulheres que se organizam para fazer frente e lutar contra as múltiplas formas de exploração e expropriação do capital - que se expressa pela ação e avanço do agronegócio, da mineração, dos grandes projetos territoriais hegemônicos que privilegiam a classe dominante.

Valorizar tais experiências que nascem no terreno popular, dos subalternos e oprimidos, requer o registro de suas práticas e atividades ao longo da história. Afinal, o que estes movimentos populares nos ensinam? 0 que trazem de dimensão e concepção filosófica como base para a transformação social? De que forma estabelecem a formação política e educativa? E se não possuem essas dimensões, como articular e construir a mobilização popular?

Tais perguntas, dentre outras que poderiam ser colocadas, partem da necessidade de estarmos mais orgânicos com as lutas populares no campo e, da mesma forma que buscar aprender com elas, poder fazer nossos balanços e avaliações críticas, afinal, também é uma tarefa essencial da classe trabalhadora ou dos seus intelectuais a avaliação permanente de suas ações, pois como afirma Ragazzini (2005, p. 93), a práxis crítica do indivíduo deve ser orientada pelo "quanto ela contribui para a solução das contradições (que não é nunca definitiva e pode levar a outras soluções) [...]".

$\mathrm{Na}$ atual conjuntura de pauperismo da classe trabalhadora, da miséria e do desemprego, do desmonte de tudo que é público (saúde, educação, cultural, arte, etc.), do descrédito às pesquisas e aos conhecimentos produzidos na academia, precisamos não somente da luta por meio das greves e das manifestações, mas recuperar o sentido e significado de sermos intelectuais-massa, isto é, ligando-nos organicamente com as massas populares, com os movimentos sociais, formando educativa e politicamente a classe a quem pertencemos, sem vaidades ou burocratismo, pois é somente no terreno popular, na base e no chão da classe oprimida, que teremos condições de derrubar o conservadorismo e o fascismo.

\section{REFERÊNCIAS}

BOITO JUNIOR, Armando. A burguesia no governo Lula. Crítica Marxista, Rio de Janeiro, n. 21, p. 52-77, primeiro semestre, 2005.

BRANFORD, Sue. Lidando com governos: o MST e as administrações de Cardoso e Lula. In: CARTER, Miguel (Org.). Combatendo a desigualdade 
social: o MST e a reforma agrária no Brasil. São Paulo: Editora UNESP, 2010. p.409-431.

GRAMSCI, Antonio. Escritos Políticos. V. III. Lisboa: Seara Nova, 1977.

GRAMSCI, Antonio A questão meriodional. Rio de Janeiro: Paz e Terra, 1987.

GRAMSCI, Antonio. Cadernos do Cárcere. V.1. Rio de Janeiro. Civilização Brasileira, 1999.

GRAMSCI, Antonio. Cadernos do Cárcere. V.2. Rio de Janeiro: Civilização Brasileira, 2001.

GRAMSCI, Antonio. Cadernos do Cárcere. V.5. Rio de Janeiro: Civilização Brasileira, 2002.

GRAMSCI, Antonio. Cadernos do Cárcere. v.3. 6a. Ed. Rio de Janeiro: Civilização Brasileira, 2014.

GUZMAN, Eduardo Sevilla. MOLINA, Manoel González. Sobre a evolução do conceito de campesinato. 2a. ed. São Paulo: Expressão Popular, 2013.

MARTINS, José de Souza. A militarização da questão agrária no Brasil (Terra e poder: o problema da terra na crise política). $2^{a}$. Ed. Petrópolis: Vozes, 1985.

MARTINS, José de Souza. Os camponeses e a política no Brasil: as lutas sociais no campo e seu lugar no processo político. 4a. Ed. Petrópolis: Vozes, 1990.

OLIVEIRA, Ariovaldo Umbelino de. Agricultura brasileira: transformações recentes. In: ROSS, Jurandyr L. Sanches (org.). Geografia do Brasil. 5a. Ed. São Paulo: EDUSP, 2005. p. 465-547.

PANINI, Carmela. Reforma agrária dentro e fora da lei: 500 anos de história inacabada. São Paulo: Paulinas, 1990.

RAGAZZINI, Dario. Teoria da personalidade na sociedade de massa: a contribuição de Gramsci. Campinas, SP: Autores Associados, 2005.

ROIO, Marcos Del. Gramsci e a emancipação do subalterno. Revista Sociologia Política, Curitiba, 29, p.63-78. Nov./2007.

SIMIONATTO, I. Gramsci: sua teoria, incidência no Brasil, influência e serviço social. Rio de Janeiro: Ed. Cortez, 2011. 
SOUZA, Celina. Estado-da-arte da pesquisa em políticas públicas. In: HOCHMAN, G.; ARRETCHE, M.; MARQUES, E. Políticas Públicas no Brasil. Rio de Janeiro: Editora Fiocruz, 2007.

Recebido em: 29 de junho de 2021. Aceito em: 16 de setembro de 2021. Publicado em: 15 de dezembro de 2021. 